\title{
HR Roles Effectiveness and HR Contributions Effectiveness: Comparing Evidence from $\mathrm{HR}$ and Line Managers
}

\author{
Yusliza Mohd.Yusoff (Corresponding author) \\ School of Management \\ Universiti Sains Malaysia \\ Minden 11800, Pulau Pinang, Malaysia \\ Tel: 60-3-5543-5847Ｅ-mail: yusliza1977@yahoo.com \\ Hazman Shah Abdullah \\ Faculty of Administrative Science \& Policy Studies \\ Universiti Teknologi MARA \\ Shah Alam 40450, Selangor, Malaysia \\ Tel: 60-3-5544-4157 E-mail: hazman@salam.uitm.edu.my
}

\author{
T. Ramayah \\ School of Management \\ Universiti Sains Malaysia \\ Minden 11800, Pulau Pinang, Malaysia \\ Tel: 60-4-653-3889Ｅ-mail: ramayah@gmail.com
}

\begin{abstract}
As the importance of human resource increases to the business, so does also the need to ensure its effective management. This study compared HR and line managers' evaluation of the effectiveness of the HR department in terms of its roles and contributions to the firm using a multi-perspective view of effectiveness. Survey responses from 108 HR and 140 line managers from 108 large manufacturing and service firms in Malaysia showed significant differences in the ratings by HR and line managers. HR managers, quite unsurprisingly, rated higher both dimensions of the HR effectiveness as compared to line managers. For a comprehensive evaluation of HRM, the study reaffirms the need for a client-centered evaluation of effectiveness given that self-assessment is always exaggerated.
\end{abstract}

Keywords: HR managers, Line managers, HR roles effectiveness, HR contributions effectiveness

\section{Introduction}

Even though the role of human resource (HR) in organizational success and sustained competitive advantage has been widely acknowledged, there is great degree of contention on how effective HR management (HRM) function is in any organization. Given the lack of clear metric of HR investment and performance, Legge (2005) suggested, without much success, that personnel managers re-invent the rules of HRM effectiveness. Since then, the field of strategic HRM has theorized and modeled HR's and HRM's impact on organizational outcomes especially financial outcomes (e.g., Chew \& Sharma, 2005; Delery \& Doty, 1996; Huselid, 1995; Huselid, Jackson, \& Schuler, 1997). Despite these efforts, HR managers are still grappling with the development of a simple but clear metric of HRM effectiveness that would excite the imagination of internal stakeholders. The concept of human capital and it being a central component in the intellectual capital of a business and the need to optimally exploit it has further added to the plethora of experiments in developing new metrics for the measurement of HRM effectiveness. HRM is, like everything else, is evolving to adopt more strategic roles. Changing roles add and/or change the metrics of HRM effectiveness in organizations (Ulrich, 
1997). Hence, efforts to assess the effectiveness of HRM must consider the many new roles HRM is asked to play. This paper seeks to examine the effectiveness of HRM in carrying out multiple roles using a client-self perspective.

\section{Literature review}

Research on multiple constituency approach to evaluate HRM effectiveness began with the research of Tsui (1984) and Salancik (1984). In particular, Tsui (1984) suggested that the tripartite framework of personnel department effectiveness need to be examined from its constituencies' perspectives. To date, information on the HRM effectiveness has been obtained primarily from HR managers (e.g., Huselid et al., 1997; Perry \& Kulik, 2008; Richard \& Johnson, 2001, 2004; Soltani, 2003; Teo, Ahmad, \& Rodwell, 2003) with little else to confirm or deny its accuracy. This increases the likelihood of social response bias since HR managers are reporting on their HRM effectiveness. Furthermore, it was supported by Guest (2001), employer reports on the HRM effectiveness from their perspective as a manager, not from their experience of the actual practices - they are not the consumers of HRM, the employee are. Unlike many studies of HRM which are based on data supplied solely by HR managers, studies adopting the multiple constituency perspective necessarily include assessments of HRM effectiveness by non-HRM staff (Geare Edgar, \& Deng, 2006; Han, Chou, Chao, \& Wright, 2006; Kane, Crawford, \& Grant, 1999; Mitsuhashi, Park, Wight, \& Chua, 2000; Teo \& Crawford, 2005; Wright, McMahan, Snell, \& Gerhart, 2001). Therefore, collecting data from HR manager as well as line manager is likely to enhance the reliability of findings reported in studies on HRM.

A study conducted by Kane et al. (1999) among 549 employees, managers, and HRM staff across a wide range of types of organizations in Australia, New Zealand, the USA, the UK, and Canada revealed the use of a multiple constituency perspective on HRM was supported, with significant differences found on the basis of the respondent's position as either HRM staff, manager or employee, and their level in the organization.

Mitsuhashi et al. (2000) investigated the differences in perceptions of the importance and effectiveness of human resources practices in firms operating in the People's Republic of China. They found that line and HR executives both viewed the issue of securing, developing, and maintaining human resources as a critical issue for the execution of daily operations and long-term strategic plans. They also found that line executives perceived HR performance effectiveness as significantly lower in that functional areas as the HR executives. Therefore, they concluded that HR departments were not meeting the performance expectations of line executives.

Besides, Wright et al. (2001) analyzed data from $44 \mathrm{HR}$ and 59 line executives from 14 companies in US. They questioned whether the differences exist between HR and line executives in evaluating the HR function along the two dimensions of HRM effectiveness. Result shows that HR executives consecutively rated the functions' effectiveness higher than line executives. Furthermore, they discovered that the greatest differences were observed on the important and/or strategic aspects of HR.

Geare et al. (2006) examined managers' and employees' evaluations of the importance and the effectiveness of the HRM function in New Zealand. Data were obtained from 35 public and private sector, based on matched manager-employee data sets. The results of their study show significant differences exist between how a manager views HRM compared to how the employees' view HRM across the two perceptual ratings (i.e., importance and effectiveness) used and across three of the four HRM functions examined. They suggested the need for a multi constituency approach for the evaluation of HRM.

Thus, this study sought to expand such research in a different cultural setting, one that is characterized by lower individualism, higher uncertainty avoidance, and higher power distance.

In this study, Wright et al.'s (2001) measure of HRM effectiveness was adapted which focuses on HR's effectiveness in performing various roles and HR's effectiveness of its contributions. The effectiveness of HR roles are captured the essence of the roles proposed by Ulrich (1997). These roles also resemble the kinds of activities that comprise Huselid et al.'s (1997) "strategic" HRM effectiveness. Specifically, Wright et al.'s (2001) measure it in terms of:

1) The "Strategic Partner" role focuses on HR's participation in and influence over the formulation strategy.

2) The "Tailoring Practices" role highlighted the role of HR in strategy implementation. It deals with tailoring HR practices to support the business strategy once it is formulated.

3) "Providing HR Services" encompasses HR's role in providing the basic services.

4) "Providing Change Consulting" refers to HR's role in helping line executives to effectively manage cultural and organisational change.

5) "Developing Organisation Skills and Capabilities" deals with HR's role in identifying and/or developing critical organisational core competencies or capabilities.

The second aspect of HRM effectiveness measure is on its contributions, and this served as more of an overall evaluation of the function. The HR contributions component is evaluated on how the HR function was being run and 
how it was contributing to the firm on different dimensions (e.g., how HR contributed to the firm's competitive position, bottom line, core competence, and human capital). These two aspects of HRM effectiveness has been used and validated in the past studies (Han et al., 2006; Mitsuhashi et al., 2000; Wright et al., 2001).

Based on the above findings, there was an expectation that there would be significant ratings differences between HR and line managers, with HR managers ratings higher than line managers ratings.

Research Question: Are HR managers ratings on the HR roles effectiveness and HR contributions effectiveness significantly higher than line managers rating?

\section{Methodology}

The data used in this study was collected as part of a larger study that investigated antecedents and outcome of empowerment of the line managers in HR activities. The mail survey approach was used in the study. Three sets of questionnaires were administered to the HR manager in the company. Each questionnaire was accompanied by a cover letter explaining the purpose of the study. HR manager was asked to complete the HR managers' survey himself/herself. Then, he/she was asked to distribute at least one copy of the line manager's questionnaire to the line manager that capable of completing the questionnaire and could represent the organization. HR managers could choose the line managers from any department in their organisation. The final sample size was 248 individuals (108 HR managers and 140 line managers) from 108 firms retained for the analysis.

Units of observation for this study are HR and line managers working in large manufacturing and service firms in Malaysia. Manufacturing firm included in the sample had 150 or more full-time employees, whilst, 50 or more full-time employees for the service companies. SMIDEC (2003) defined small and medium enterprises in manufacturing are enterprises with full-time employees not exceeding 150 , whereas small and medium enterprises in the services sectors are enterprises with full-time employees not exceeding 50.

\subsection{Measures}

\subsubsection{HR Roles Effectiveness}

Five items of the HR roles gauged the effectiveness of the HR function in terms of the roles "providing HR services", "providing change consulting services", "being a business partner", "developing organisation skills and capabilities", and "tailoring practices to fit business needs". The roles were assessed on a seven-point scale with 1 (not meeting needs) to 7 (all needs met) scale.

\subsubsection{HR Contributions Effectiveness}

The 10-item the effectiveness of the HR contributions developed by Wright et al. (2001) was used to measure the overall effectiveness of the HR function. The rating was on a seven-point Likert scale, ranging from $1=$ 'not at all' to 7 $=$ 'to a great extent'.

\section{Results}

The aim of this paper was to examine whether there is a significant difference between HR and line managers towards the perceptions of HR roles effectiveness and HR contributions effectiveness in large manufacturing and service firms in Malaysia. A total of 108 companies responded to the survey (108 from HR managers and 140 from line managers). The organizations were classified into two main industries in Malaysia: manufacturing and services. Manufacturing firms accounted for 61.1 percent of the sample. The services firms accounted for another 38.9 percent of the sample.

As shown in Table 1, reliability estimates using Cronbach's alphas for the HR roles effectiveness and HR contributions effectiveness measures were 0.82 and 0.94 , respectively. All of the final HR effectiveness scales have acceptable internal reliability according to Nunnally's (1978) 0.7 criterions.

As can be seen in Figure 1, HR and line managers differ with regard to their perception of the extent to which the HR function is adequately fulfilling its various roles. HR and line managers agreed with regard to what role HR is best fulfilling (providing HR services) and least is (business partner). However, significant differences were observed for all five roles, with HR managers giving between 0.22 and 0.60 scale points higher ratings on these items relative to the line managers.

With regard to the HR contributions, as can be seen in Figure 2, there were also significant differences between HR and line managers in the rated effectiveness of the overall contributions of the HR function. HR managers gave the highest effectiveness ratings on the items of providing timely HR information (mean $=5.58$ ), while value-added contributions $($ mean $=4.56)$, enhancing competitive position (mean=4.60), performing the expected job (mean=4.64) and maintaining firm's core competence $($ mean $=4.69)$ received the four lowest ratings from line managers.

To test whether differences in "Position" affect HR effectiveness differently, an independent-samples T-test was conducted for responses from HR and line managers using SPSS. Table 2 shows that the mean values on the construct of HR roles effectiveness for HR and line managers are 5.19 and 4.80, respectively, with $\mathrm{T}$ value of 3.15 and 
significance level of less than 0.01 . Meanwhile, the mean value on the HR contributions effectiveness measure for HR managers is 5.35 , while line managers are 4.82 . The $\mathrm{T}$ value is 4.50 at the significance level of less than 0.01 . Thus, there is significant difference between HR and line managers in respect to the two dimensions of HRM effectiveness.

\section{Discussion}

The aim of this study is seek to find the differences on the perceptions of HR roles effectiveness and HR contributions effectiveness among $108 \mathrm{HR}$ managers and 140 line managers in the 108 Malaysian large manufacturing and service firms. In general, the findings showed significant differences between HR and line managers. HR managers were rated higher for both dimensions of the HR effectiveness as compared to line managers. The results of this study are congruent with the finding of previous studies related to differences in perceptions of the HR effectiveness where line executives do not rate HR effectiveness as highly as HR executives (Mitsuhashi et al., 2000; Wright et al.. 2001).

On the HR manager's side, this finding can be explained in two ways. First, they may be positioned at the senior committee level but if they are not committed to understanding the HR department, their contribution is devalued accordingly. If they can show that they have run a business, it is possible that they will have credibility in the HR department. Secondly, the difference in perceptions have been found to occur because of a tendency for [HR] team members to overestimate the effectiveness of their performance as compared to ratings from internal customers (Gilbert, 2000; Phelps, 2002). Thus, the above mentioned reasons provide support for the notion that HR managers have higher assessment in their perceptions of the effectiveness of the HR department.

On the side of the line managers, the differences may be due to HR-line conflict. Line managers did not an express in taking on more HR responsibilities and view it as a having as critical a relationship to firm success as the line function. In addition, previous research by Phelps (2002) concludes that non-HR managers have a negative view of the function, and relates findings about the performance of HR professionals on a range of people-related processes as 'consistently failing to meet the requirements' of non-HR managers'. Given this, it is not surprising that they would have a tendency toward evaluating HR department as not being overly effective.

One technique for Malaysian organisations to reduce the HR effectiveness gap is to form partnerships between HR managers and line managers. This partnership allows HR better understand the manager's business needs, which in turn, enables HR to be a more value-added resource. This partnership has been valuable for two main reasons. First, the HR staff now understands what drives their business; therefore, if a change is required, HR now knows from the line manager's position what is driving the need for that change. Secondly, HR managers gain a more balanced view of the business; therefore, they are better able to balance business needs with employee needs.

Perhaps, the emerging concept of 'strategic partner' (Bhatnagar \& Sharma, 2005; Buyen \& de Vos, 2001; Lawler \& Mohrman, 2000; Ulrich, 1997; Wright, Dyer \& Takla 1999) contends that HR departments should help line managers resolve business issues and align HR interests with the achievement of organizational goals. Line managers are important for successful policy implementation in organizational change situations, as vital communication link between senior management and team members (McHugh, O'Brien, \& Ramondt, 1999). Therefore, close collaboration between HR and line managers can determine the most effective evaluation of the HR department as well as can create synergies, which add value to the company.

\section{Conclusion}

In conclusion, this study contributes toward the literature on the effectiveness of the HR departments. This study is the first one undertaken in the Malaysian manufacturing and service firms with emphasis on the differences in the perceptions of HRM effectiveness between HR and line managers. This study has covered the first part. Building on the work of earlier researchers in the field, such as Wright and associates, it has analyzed the extent to the differences of HRM effectiveness is applied in Malaysian organisations and has helped to evaluate the present scenario.

Further, access to HR and line managers' perceptions of the effectiveness of the HR department has been a useful first stage in the measurement and management of $\mathrm{HC}$ as a high level strategic issue within the two large organizations in Malaysia. HRM effectiveness, as an area of academic research is relatively recent, however is an organizational issue in Malaysia (particularly in large manufacturing and service firms) that will attract increasing attention for the foreseeable future. Potential areas for future academic research could include an exploration of how Malaysia firms are actually reporting on their $\mathrm{HC}$ of measuring HRM effectiveness which, over time, would add a significant contribution to more conceptually and empirically based research in this emergent area.

\section{References}

Bhatnagar, J., \& Sharma, A. (2005). The Indian perspective of strategic HR roles and organizational learning capability. International Journal of Human Resource Management, 16(9), 1711-1739.

Buyens, D., \& de Vos, A. (2001). Perception of the value of the HR function. Human Resource Management Journal, 11(3), 70-89. 
Chew, I. K. H., \& Sharma, B. (2005). The effects of culture and HRM practices on firm performance: Empirical evidence from Singapore. International Journal of Manpower, 26(6), 560-581.

Delery, J. E., \& Doty, D. H. (1996). Modes of theorizing in strategic human resource management: Tests of universalistic, contingency, and configurational performance predictions. Academy of Management Journal, 39(4), 802-835.

Geare, A., Edgar, F., \& Deng, M. (2006). Implementation and consumption of HRM: Stakeholder differences. Research and Practice in Human Resource Management, 14(2), 34-48.

Gilbert, J. T. (2000). Sorrow and guilt: An ethical analysis of layoffs. S.A.M. Advanced Management Journal, 65(2), 4-13.

Guest, D. E. (2001). Human resource management: When research confronts theory. The International Journal of Human Resource Management, 12(7), 1092-1106.

Han, J., Chou, P., Chao, M., \& Wright, P. M. (2006). The HR competencies-HR effectiveness link: A study in Taiwanese high-tech companies. Human Resource Management, 45(3), 391-406.

Huselid, M. A, Jackson, S. E., \& Schuler, R. S. (1997). Technical and strategic human resource management effectiveness as determinants of firm performance. Academy of Management Journal, 40(1), 171-188.

Huselid, M. A. (1995). The impact of human resource management practices on turnover, productivity, and corporate financial performance. Academy of Management Journal, 38(3), 635-672.

Kane, B., Crawford, J., \& Grant, D. (1999). Barriers to effective HRM. International Journal of Manpower, 20(8), 494-515.

Lawler, E. E., \& Mohrman, S. A. (2000). Beyond the vision: What makes HR effective? Human Resource Planning, 23(4), $10-20$.

Legge, K. (2005). Human resource management: Rhetorics and realities. New York, N.Y.: Palgrave Macmilan.

McHugh, M., O'Brien, G., \& Ramondt, J. (1999). Organizational metamorphosis led by front line staff. Employee Relations, 21(6),556.

Mitsuhashi, H., Park, H. J., Wright, P. M., \& Chua, R. S. (2000). Line and HR executives' perceptions of HR effectiveness in firms in the People's Republic of China. International Journal of Human Resource Management, 11(2), 197-216.

Nunnally, J. C. (1978) Psychometric theory, McGraw Hill, New York.

Perry, E. L., \& Kulik, C. T. (2008). The devolution of HR to the line: Implications for perceptions of people management effectiveness. The International Journal of Human Resource Management, 19(2), 262-273.

Phelps, A. (2002). Beyond best value. People Management, 25 July, 52.

Richard, O. C., \& Johnson, N. B. (2001). Strategic human resource management effectiveness and firm performance. International Journal of Human Resource Management, 12(2), 299-310.

Richard, O. C., \& Johnson, N. B. (2004). High performance work practices and human resource management effectiveness: Substitutes or complements? Journal of Business Strategies, 21(2), 133-148.

Salancik, G. R. (1984). A single value function for evaluating organizations with multiple constituencies. Academy of Management Review, 9(4), 617-625.

SMIDEC (2003). [Online] Available: http://www.smidec.gov.my/detailpage.jsp?page=defsme.

Soltani, E. (2003). Towards a TQM-driven HR performance evaluation: An empirical study. Employee Relations, 25(4), 347-370.

Teo, S. T. T., \& Crawford, J. (2005). Indicators of strategic HRM effectiveness: A case study of an Australian public sector agency during commercialization. Public Personnel Management, 34(1), 1-16.

Teo, S. T. T., Ahmad, T., \& Rodwell, J. J. (2003). HR role effectiveness and organizational culture in Australian local government. Asia Pacific Journal of Human Resources, 41(3), 298-315.

Tsui, A. S. (1984). Personnel department effectiveness: A tripartite approach. Industrial Relations, 23(2), 184-197.

Ulrich, D. (1997). Human resource champions: The next agenda for adding value and delivering results, Harvard Business School Press, Boston.

Wright, P. M., Dyer, L., \& Takla, M. G. (1999). What's next? Key findings from the 1999 state-of-the-art \& practice study. Human Resource Planning, 22(4), 12-20.

Wright, P. M., McMahan, G. C., Snell, S. A., \& Gerhart, B. (2001). Comparing line and HR executives' perceptions of HR effectiveness: Services, roles, and contributions. Human Resource Management, 40(2), 111-123. 
Table 1. Reliability coefficients

\begin{tabular}{c|c|c}
\hline Variables & Number of Items & Cronbach's Alpha \\
\hline HR Roles Effectiveness & 5 & .82 \\
\hline HR Contributions Effectiveness & 10 & .94 \\
\hline
\end{tabular}

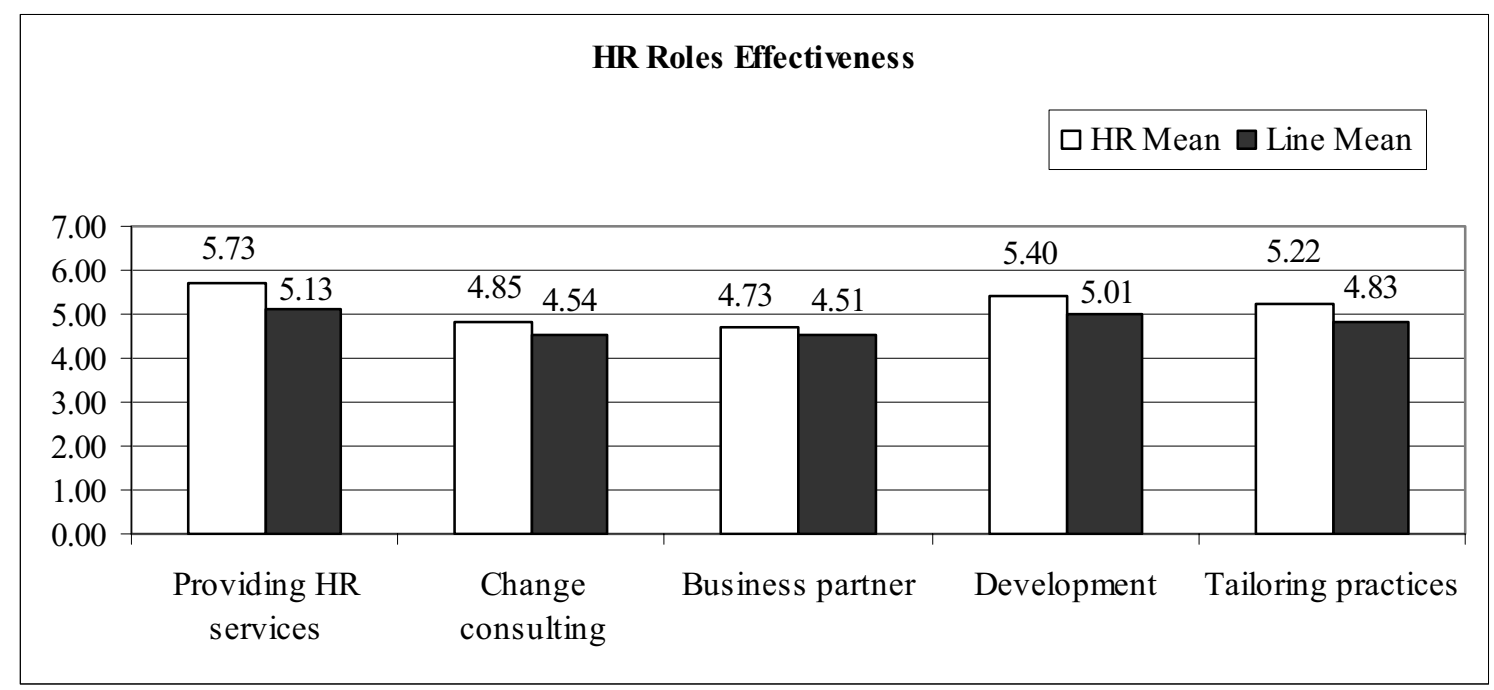

Figure 1. HR Roles Effectiveness

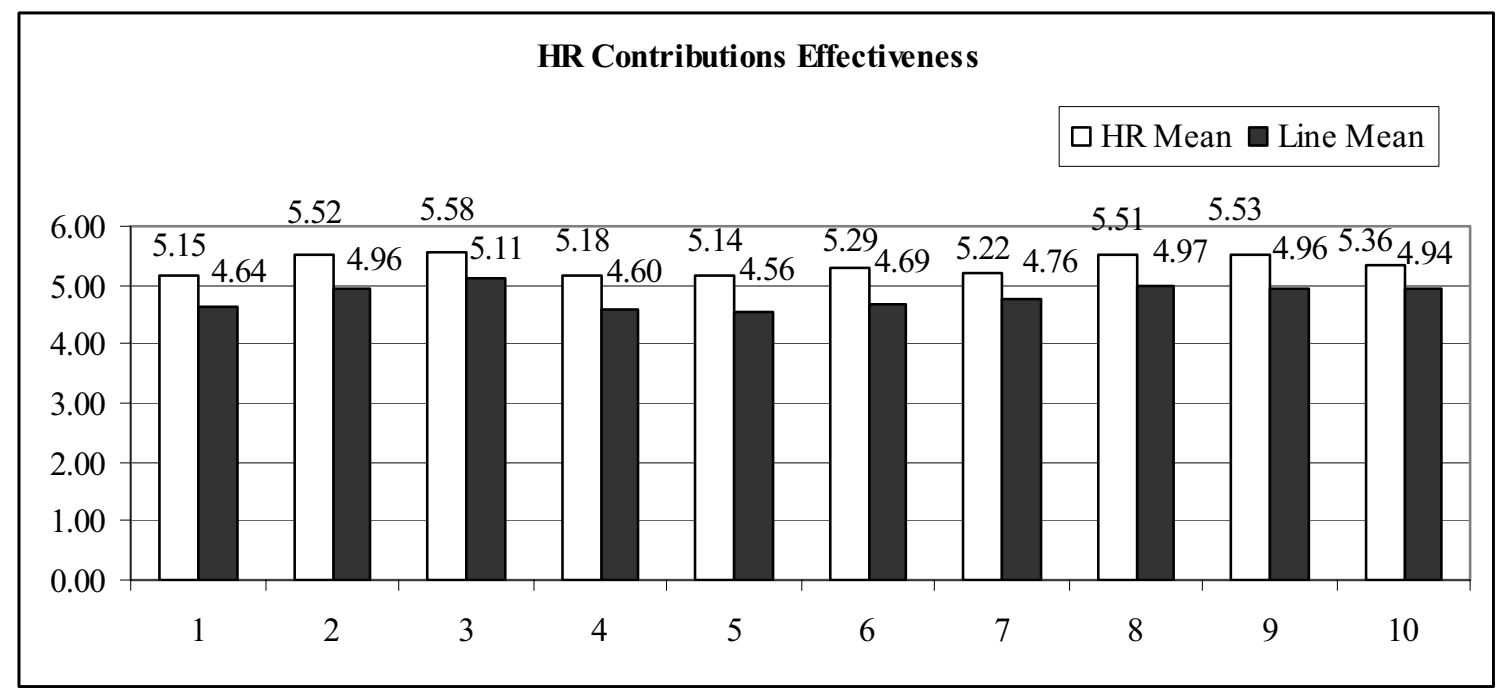

Figure 2. HR Contributions Effectiveness

Notes: 1 = Performing the expected job; 2 = Responsive to front-line managers' and employees' needs; $3=$ Provide timely HR information; $4=$ Enhancing competitive position; $5=$ Value-added contribution; $6=$ Maintaining firm's core competence; 7 = Source of competitive advantage; 8 = Policies, practices, and procedures helps employees; 9 = Developed a well coordinated policies, practices, and procedures; $10=$ Support firm's business plan.

Table 2. Differences in the HR effectiveness measure by HR and Line managers

\begin{tabular}{c|c|c|c}
\hline Variables & $\begin{array}{c}\text { HR Manager } \\
\text { (Mean) }\end{array}$ & $\begin{array}{c}\text { Line Manager } \\
\text { (Mean) }\end{array}$ & t-value \\
\hline HR Roles Effectiveness & 5.19 & 4.80 & $3.15^{* *}$ \\
\hline HR Contributions Effectiveness & 5.35 & 4.82 & $4.50^{* *}$ \\
\hline
\end{tabular}

$* \mathrm{p}<0.1, * * \mathrm{p}<0.01$ 